\title{
Perfis bioquímicos e imunológicos no período peripartal de vacas leiteiras com e sem retenção de placenta
}

CORRESPONDENCE TO: Luiz Ernandes Kozicki Departamento de Medicina Veterinária - Setor de Ciências Agrárias Universidade Federal Agrasias. Universidade Federal do Paraná - Caixa Postal 2959 Rua Jaime Balão, 575 , Bairro Hugo Lange, 80040-340 Curitiba - PA - Brasil

1 - EMATER, $P R$ 2 - Departamento de Medicina Veterinária, Setor de Ciências Agrárias, UFPR - Curitiba - PR

\author{
Dicezar GONÇALVES'; Luiz Ernandes KOZICKI ${ }^{2}$
}

\section{RESUMO}

Foram determinados alguns perfis bioquímicos e imunológicos em 16 vacas holandesas com retenção de placenta (RP) e 23 sem retenção (NRP) de 241 partos observados. A alimentação dos animais era baseada em forragens cultivadas no inverno e verão, silagem de milho, feno e concentrado com $18,0 \%$ de proteína bruta e $70,0 \%$ de nutrientes digestíveis totais. As determinações dos componentes plasmáticos no período peripartal (dias $-15,-5$, dia do parto, +3 e +5 ) revelaram maiores concentrações de colesterol $(p<0,01)$, fósforo $(p<0,01)$, fosfatase alcalina $(p<0,05)$, desidrogenase láctica $(p<0,05)$, aspartatoaminotransferase, uréia, fosfatase ácida e menores niveis de cálcio em vacas RP. As proteínas totais estiveram dentro dos padrões fisiológicos em ambos os grupos. Os niveis de imunoglobulinas demonstraram a incapacidade das vacas $\mathrm{RP}$ de produzir $\lg M$, IgG sangüíneas $(p<0,001)$ e $\lg A$ no colostro e no leite $(p<0,01)$ quando comparadas às vacas NRP. As RP aprerentaram, no dia da parturição, quadro de neutrofilia, eosinofilia, monocitose e linfocitose, revelando imunodepressão $\uparrow$,riférica, quando comparadas com as NRP. Observaram-se complicações nas vacas RP, com $87,5 \%$ de endometrite e $62,5 \%$ 'ie mastite aguda, demonstrando que estas eram mais susceptíveis. Os resultados reforçam a existência de relação estreila entre a produção de imunoglobulinas, número de leucócitos, retenção de placenta, inflamação do útero e da glândula mamári ', tornando possível a previsão de retenção dos anexos fetais 15 dias antes do parto nas vacas de leite.

UNITERMOS: Vacas leiteiras; Retenção placenta; Mastite; Parto.

\section{INTRODUÇÃO E REVISÃo BIBLIOGRÁFICA}

A incidência de retenção de placenta nos bovinos situa-se entre $7,0 \%$ e $12,0 \%$ 40.41, acarretando prejuízos à pecuária. em virtude de maior intervalo/parto-concepção, irregulares ciclos estrais, mortalidade embrionária, infertilidade causadas por endometrite, metrite, piometra, bem como a queda na produção de leite, perdas de mamas produtivas ${ }^{25}$ e descarte de valiosos animais.

Atrelado à problemática da retenção do anexos fetais, o cálcio ( $\mathrm{Ca}$ ) torna-se importante no evento do parto ${ }^{35}$, porque sua deficiência está relacionada à retenção de placenta, sendo recomendada a suplementação por Capaul; Luca ${ }^{2}$ (1984). Kumpf ${ }^{21}$ ( 1985) demonstrou estar a concentração do Ca mais elevada nas vacas NRP.

Kumpf $^{21}$ (1985), Vukovik et al. ${ }^{39}$ (1987) e Kamiya; Daigo ${ }^{17}$ ( 1988 ) relatam a importância do fósforo $(\mathrm{P})$ no metabolismo celular da placenta, em virtude de sua ligação ao metabolismo energético, sendo detectados níveis maiores em vacas $\mathrm{RP}^{21}$.

Kumpfil (1985) determinou níveis da aspartatoaminotransferase (AST) em dois grupos de animais, verificando valores mais elevados nas RP.

A desidrogenase láctica (LDH) foi verificada em níveis elevados na fase do estro e no período peripartal dos animais. Seu aumento foi marcante nas vacas $R^{6}$ e concluiu-se que o aumento de LDH é indicativo de endometrite, antes do aparecimento dos sinais específicos desta afecção.
Kummer et al. ${ }^{20}$ (1987) determinaram a fosfatase ácida (ACP) em placentomas de vacas, imediatamente após o parto, observando que a sua atividade era maior nos partos normais.

Dutta; Dugwekar6 (1982) e Sala ${ }^{31}$ (1988) verificaram aumentos dos níveis da fosfatase alcalina (ALP) em alguns problemas patológicos. Seu aumento está associado à necrose dos vilos coriônicos e das criptas carunculares, encontrando-se aumentada até o quinto dia após o parto, quando há retenção de placenta'.

Chassagne; Barnouin (1992) verificaram que vacas NRP apresentaram perfis mais elevados de colesterol em relação às $R P$.

Os valores da uréia no soro de bovinos estão aumentados em virtude de processos degenerativos da placenta segundo Lotthammer ${ }^{23}$ (1984). Vacas RP apresentaram valores mais elevados de uréia e de proteínas totais (PT) de acordo com Chassagne; Barnouin $^{3}$ (1992). Estes autores determinaram os níveis de albumina sérica e demonstraram que animais NRP apresentam perfis mais elevados desta proteína.

A respeito da avaliação do estado imunológico Ehlert ${ }^{8}$ (1985), Gunnink $^{14}$ (1984) e Heuwieser; Grunert ${ }^{16}$ (1987) relataram haver baixa infiltração leucocitária nos cotilédones de vacas RP. Gunnink ${ }^{14}$ (1984) confirmou a redução de células polimorfonucleares nos casos de retenção de placenta e elevadas quantidades de neutrófilos no útero no parto normal. Graen ${ }^{13}$ (1985) verificou valores elevados de leucócitos circulantes e fagócitos nos partos normais de vacas, decrescendo 24 horas após.

A imunoglobulina A ( $\operatorname{Ig} \mathrm{A})$ é produzida por linfócitos e é 
fundamental em conjunto com neutrófilos e fagócitos para a defesa de epitélio e mucosas ${ }^{37}$.

A importância da imunoglobulina M (IgM) no soro, colostro e leite de vacas RP é fundamental, porque as determinações imunológicas elucidariam o momento do aparecimento de mastite segundo Roitt; Brostoff ${ }^{34}$ ( 1989), Klein ${ }^{18}$ (1990) e Roitt ${ }^{30}$ (1991). Gonçalves; Kozicki'2 (1993) determinaram os teores das imunoglobulinas $\mathrm{M}, \mathrm{G}$ e $\mathrm{A}$ no soro de vacas RP e NRP no dia do parto, que se apresentaram significativamente mais elevados nos animais NRP.

A ocorrência de mastite no puerpério precoce de vacas, associada à retenção de placenta, foi comprovada por Schukken el al. $^{34}$ (1989), Schukken ${ }^{33}$ (1989), Heinonen; Heinonen ${ }^{15}$ (1991) e Lescourret et al. ${ }^{22}$ (1995). Os primeiros autores observaram frequêencia de $10,0 \%$ a $15,0 \%$ de mastite nos animais RP, demonstrando a relação com o sistema imune.

A presente investigação objetivou levantar os perfis bioquímicos e imunológicos em vacas, com a finalidade de prevenção da retenção de placenta antes do parto, e verificar a existência de relação entre retenção de placenta e mastite.

\section{MATERIAL E MÉTODO}

\section{Animais pesquisados e sistema de manejo}

A pesquisa foi realizada em fazendas situadas na região metropolitana de Curitiba (PR), com 241 parturições. Deste total foram estudadas 39 vacas $(25,6 \%$ primíparas, $23,2 \%$ secundíparas e $51,2 \%$ pluríparas), as quais apresentavam bom escore corporal $(82,0 \%)$ e regular $(17,9 \%)$ segundo Edmondson ${ }^{7}$ (1992).
Os animais alimentavam-se de pastagens de inverno e verão, silagem de milho (20 kg/animal), resíduos de cevada e feno. Adicionalmente recebiam $1,0 \mathrm{~kg}$ de concentrado com $18,(1 \%) \mathrm{de}$ proteína e $70,0 \%$ de nutrientes digestíveis totais, para cada 3 litros de leite produzidos. Os animais eram individualmente protocolados e examinados clinicamente no $15^{\circ}$ e $5^{\circ}$ dia antes. no dia e no $3^{\circ}$ e $5^{\circ}$ dias após o parto. Considerou-se retenção de placenta o tempo de 12 horas sem expulsão ${ }^{40}$.

\section{Determinações bioquímicas no sangue}

Foram colhidas amostras de sangue de 39 animais $(16 \mathrm{com}$ e 23 sem retenção de placenta) nos dias - 15,-5, dia do parto (0), +3 , +5 após o parto. Foram determinados no soro sanguíneo (emprego de kits Labtest e Merck): cálcio, fósforo, proteínas totais, albumina, colesterol, uréia, fosfatase alcalina, fosfatase ácida, desidrogenase láctica, aspartatoaminotransferase.

Foi realizada a eletroforese das proteínas plasmáticas no soro bovino em 4 animais do grupo com RP e 4 NRP (técnica de Kohn"1", 1976 ) utilizando-se fitas de acetato de celulose (Lab.Cellogel, Italia). Foi igualmente determinado o conteúdo de imunoglobulinas (M,G,A) no soro sangüíneo de 8 animais com e 8 sem retenção nos dias $-15,-5,0,+3,+5$ após parto, no colostro (dia ()) e no leite $(+3,+5)$. A técnica empregada foi a imunodifusão radial (kits VMRD,USA), segundo Crowlet (1961) e Fahey; McKelvey" (1965). Foram realizados leucogramas no dia do parto.

Paralelamente foram processados exames do leite com o California Mastitis Test (CMT) no $3^{\circ}$ e $5^{\circ}$ dias pós-parto. As amostras reagentes positivas eram colhidas, para posteriormente serem submetidas à cultura e antibiograma de acordo com Quinn ${ }^{28}$ ( 1994).

Tabela 1

Padrões bioquímicos séricos em vacas holandesas, variedade preta-e-branca, NRP e RP, no $-15^{\circ},-5^{\circ}, 0,+3^{\circ},+5^{\circ}$ dias post partum $(n=39)$. (Curitiba, Paraná, 1994),

\begin{tabular}{|c|c|c|c|c|c|c|}
\hline DETERMINAÇÕES & $\begin{array}{c}\text { DIAS } \\
\text { GRUPO }\end{array}$ & $-15^{\circ}$ & $-5^{\circ}$ & 0 & $+3^{\circ}$ & $+5^{\mathrm{Q}}$ \\
\hline $\mathrm{Ca}$ & NRP & $11,3 \pm 1,5$ & $10,8 \pm 1,6$ & $9,9 \pm 1,5$ & $9,8 \pm 1,6$ & $9,6 \pm 1,6$ \\
\hline $\bar{P}$ & NRP & $5,4 \pm 0,8$ & $5,3 \pm 0,8$ & $5,4 \pm 1,1$ & $5,6 \pm 1,1$ & $5,5 \pm 1,2$ \\
\hline $\mathrm{mg} / \mathrm{dl}$ & RP & $6,0 \pm 1,1$ & $5,9 \pm 1,0$ & $5,8 \pm 0,7$ & $5,8 \pm 1,0$ & $5,9 \pm 1,1$ \\
\hline Prot.Totais & $\overline{N R P}$ & $6,7 \pm 1,0$ & $6,8 \pm 0,8$ & $6,9 \pm 0,9$ & $6,7 \pm 1,0$ & $6,8 \pm 1,2$ \\
\hline albumina & NRP & $4,8 \pm 0,6$ & $4,4 \pm 0,1$ & $4,5 \pm 0,7$ & $4,0 \pm 0,8$ & $3,7 \pm 0,8$ \\
\hline$g / d l$ & $\mathrm{RP}$ & $4,8 \pm 0,5$ & $4,9 \pm 0,6$ & $4,5 \pm 0,7$ & $4,1 \pm 0,7$ & $3,8 \pm 0,9$ \\
\hline colesterol & $\overline{\mathrm{NRP}}$ & $99,8 \pm 29,0$ & $112,6 \pm 19,8$ & $105,1 \pm 29,1$ & $91,8 \pm 26,8$ & $75,0 \pm 28,5$ \\
\hline $\mathrm{mg} / \mathrm{dl}$ & RP & $\uparrow 17,2 \pm 45,8$ & $128,3 \pm 51,9$ & $112,5 \pm 27,2$ & $104,3 \pm 22,6$ & $85,1 \pm 31,4$ \\
\hline uréia & NRP & $33,5 \pm 18,7$ & $42,9 \pm 18,8$ & $42,7 \pm 21,0$ & $42,2 \pm 16,0$ & $64,1 \pm 30,4$ \\
\hline $\mathrm{mg} / \mathrm{dl}$ & $\mathrm{RP}$ & $29,5 \pm 14,6$ & $45,7 \pm 20,5$ & $74,2 \pm 61,5$ & $76,5 \pm 35,0$ & $78,5 \pm 23,6$ \\
\hline $\mathrm{U} / \mathrm{dl}$ & RP & $2,5 \pm 1,9$ & $5,3 \pm 3,0$ & $4,6 \pm 2,6$ & $3,4 \pm 2,6$ & $2,1 \pm 1,2$ \\
\hline$\overline{\mathrm{LDH}}$ & NRP & $551,4 \pm 127,1$ & $622,3 \pm 120,3$ & $691,6 \pm 180,3$ & $713,7 \pm 216,0$ & $735,9 \pm 227,1$ \\
\hline $\mathrm{U} / \mathrm{dl}$ & $\mathrm{RP}$ & $596,7 \pm 153,0$ & $642,4 \pm 160,5$ & $754,5 \pm 112,4$ & $810,4 \pm 137,5$ & $729,6 \pm 119,8$ \\
\hline$\overline{\text { AST }}$ & NRP & $48,6 \pm 19,8$ & $58,3 \pm 20,6$ & $51,6 \pm 12,5$ & $51,0 \pm 17,5$ & $46,9 \pm 23,3$ \\
\hline $\mathrm{U} / \mathrm{dl}$ & RP & $42,6 \pm 9,9$ & $62,5 \pm 25,0$ & $59,7 \pm 16,0$ & $59,5 \pm 19,9$ & $55,5 \pm 34,6$ \\
\hline
\end{tabular}

NRP = sem retenção de placenta; RP = retenção de placenta 
Cálculos estatísticos empregados: média, análise da variância, teste " $t$ " de Student, teste do qui-quadrado e análise de regressão.

\section{RESULTADOS E DISCUSSÃo}

Os níveis de Ca, segundo Fayez et al. ${ }^{10}(1982)$, Martin et al. ${ }^{24}$ (1982), Capaul; Luca ${ }^{2}$ (1984), Kumpf ${ }^{21}$ (1985) e Ver et al. ${ }^{38}$ (1989), diminuem fisiologicamente nas vacas NRP, demonstrando que a sua demanda no período peripartal é grande. Os resultados verificados coincidem com os destes autores, pois animais do grupo RP (Tab. 1 ) apresentaram níveis abaixo do fisiológico nos dias -15 e -5, sugerindo maior atividade do parato-hormônio (indiretamente medido pela ALP) de acordo com Bacila' (1980). É possível que, abaixo destas concentrações, surgissem problemas metabólicos. Os animais NRP apresentaram concentrações dentro dos padrões fisiológicos( 10 a $12 \mathrm{mg} / \mathrm{dl}$ ), embora do dia do parto ao $5^{\circ}$ dia estivessem aquém do normal e a ALP ultrapassasse 50 U/l, comprovando a elevada demanda do mineral. Estes animais não evidenciaram problemas que poderiam explicar a elevação da atividade enzimática segundo Dutta; Dugwekar ${ }^{\circ}$ ( 1982) e Kummer et al. ${ }^{20}$ (1985). O perfil pré-parto subnormal de cálcio constitui elemento valioso na prevenção da retenção de placenta.

Segundo Kumpf ${ }^{21}$ ( 1985 ) o cálcio não prejudica a absorção de fósforo nas vacas e este é importante na formação de ATPs ${ }^{36}$. Os resultados deste experimento (Tab. 1) coincidem com os de Kumpf ${ }^{21}$ (1985) e Vukovik et al. ${ }^{39}$ (1987), demonstrando que níveis elevados de $P$ nos animais RP no período peripartal são indicativos de metabolismo deficiente. São escassas as publicações a respeito da relação $\mathrm{Ca} / \mathrm{P}$ neste período. Os padrões físiológicos da relação $\mathrm{Ca}: \mathrm{P}$ (2:1) citados por Bacila' (1980) encontravam-se alterados nos animais RP, quando foi detectada a relação de $1,6: 1$ e padrões normais para os animais NRP antes da parturição. O elevado consumo de Ca a partir do parto no grupo NRP baixou a relação, antes fisiológica, para níveis de 1,7:1, sugerindo a necessidade de suplementação às parturientes.

Chassagne; Barnouin ${ }^{3}$ (1992) reportaram valores de 7,6 e $8.5 \mathrm{~g} / \mathrm{dl}$ das proteínas totais, no plasma de vacas NRP e RP respectivamente, elucidando aspectos nutricionais, bioquímicos e fisiológicos. Os autores determinaram as proteínas totais, colesterol, uréia, glicose, outros componentes plasmáticos e prostaglandinas pela sua ação na parturição. Os resultados encontrados demonstraram concentrações proteicas mais elevadas em vacas RP. Os resultados deste experimento complementam os de Chassagne; Barnouin'(1992), evidenciando que, no puerpério de vacas leiteiras com RP. há excessivo gasto de proteínas, reduzindo os níveis físiológicos para 5,8 e $6,5 \mathrm{~g} / \mathrm{dl}$ no $3^{\circ}$ e $5^{\circ}$ dias após o parto, respectivamente, confirmados pelos aumentos nas taxas de uréia, forma de o organismo animal excretar seus excessos de nitrogênio, segundo Oliveira et $a l .^{27}$ (1985) e Silveira et $a l .{ }^{36}$ (1988). Os estudos sobre as frações protcicas efetuados neste experimento (relação albumina/globulina) possibilitaram prever a ocorrência da retenção da placenta.

Wagner $^{10}$ (1989), Chassagne; Barnouin ${ }^{3}$ (1992) relatam a importância da albumina no estudo da retenção de placenta, tal como a de ligar-se ao cálcio, transportar hormônios e ácidos graxos poliinsaturados. As taxas elevadas desta proteína em vacas RP, associadas à deficiência de cálcio e ao desequilíbrio de ácidos graxos poli- insaturados na dieta pré-parto, revelaram problemas na cascata do ácido aracdônico e na produção de anticorpos. Neste estudo demonstrou-se maior proporção de albumina nas vacas $\mathrm{RP}(>4,0 \mathrm{~g} / \mathrm{dl})$ $(p>0,01)$, relacionada à menor taxa de globulina verificada (Tab. 1).

Diversos relatos apontam a importância do colesterol no estudo da retenção de placenta, porque os hormônios esteróides são sintetizados também a partir de suas moléculas ${ }^{35+10}$. Concordando com relatos de Oliveira et al. ${ }^{27}$ (1985), as taxas de colesterol verificadas neste estudo revelaram concentrações mais elevadas nas vacas $R P(p<0,05)$, durante o período peripartal, embora apenas um dos resultados estivesse acima da normalidade $(128,3 \mathrm{mg} / \mathrm{dl})$ no $5^{\circ}$ dia antes da parturição. Considerando a utilização de animais de diferentes idades, a Tab. 1 mostra a média variando de 26 a 144 meses. Ao se determinar o colesterol, a faixa etária dos animais deve ser considerada, pois taxas elevadas nem sempre são indicativas de retenção de placenta. A prevenção da retenção através de determinações do colesterol deve considerar o seguinte: a) vacas até 40 meses de idade que expulsam a placenta apresentam perfil entre 80 e $100 \mathrm{mg} / \mathrm{dl}$, ao passo que as vacas com RP terão 85 a $110 \mathrm{mg} / \mathrm{dl}$; b) idades entre 41 e 80 meses apresentam perfil entre 90 e $110 \mathrm{mg} /$ dl contra 100 e $130 \mathrm{mg} / \mathrm{dl}$, para vacas NRP e RP respectivamente; c) faixa etária entre 81 e 100 meses apresenta taxas entre 95 e 120 $\mathrm{mg} / \mathrm{dl}$ para animais NRP e 110 a $140 \mathrm{mg} / \mathrm{dl}$ para vacas RP. A observação destes parâmetros do colesterol permitirá prever a ocorrência de RP.

Chassagne; Barnouin ${ }^{3}$ (1992) relataram que a taxa de uréia em animais RP e NRP foi de $31,3 \mathrm{mg} / \mathrm{dl}$ e $29,2 \mathrm{mg} / \mathrm{dl}$, respectivamente, diferente do resultado do presente trabalho relativamente ao $15^{\circ}$ dia pré-parto (Tab. 1). Nossos resultados são concordantes com os de Lotthammer ${ }^{23}$ (1984) entre o $5^{\circ}$ dia antes e o $5^{\circ}$ após o parto. O aumento das concentrações plasmáticas de uréia ocorreu em ambos os grupos, sobretudo no grupo RP, atingindo 4 vezes mais que o fisiológico. Do ponto de vista nutricional, $17,8 \%$ das vacas recebiam alimentos com elevado teor proteico e as demais eram submetidas a dietas adequadas e nível de energia mais elevado. Isso sugere que aumentos nas taxas de uréia devem-se a processos degenerativos da placenta e a alterações como endometrite, metrite e mastite, que segundo Silveira ${ }^{36}$ (1988) eleva a excreção de nitrogênio. A determinação de uréia em vacas RP permitiu antecipar a ocorrência desta afecção antes mesmo do aparecimento dos sinais clínicos, pois nas dosagens foram observados níveis mais elevados nestes animais.

Aumentos da atividade da fosfatase alcalina no soro e no epitélio placentário ${ }^{20}$ foram igualmente determinados neste experimento. Os resultados coincidem com os dos autores (Tab. 1) e confirmam que o aumento da atividade da enzima está relacionado a determinadas condições como a presença da ALP nas células placentárias maternais e fetais e destruição destas, advindo o quadro bioquímico observado; e no soro de parturientes em virtude do metabolismo do tecido ósseo, em que o parato-hôrmonio retira o cálcio necessário para atender à demanda do mineral na parturição, evitando doenças metabólicas no puerpério'. Os problemas patológicos das vacas com RP seriam os responsáveis pelo excedente de ALP, ao se compararem os perfis dos grupos de animais, concordando com os trabalhos de Dutta; Dugwekar' (1982) e Kummer ef al. 20 (1985). A determinação da ALP pode orientar na suplementação de cálcio e vitamina $D$ às parturientes e prever a ocorrência de RP segundo nossos dados. 
Em relação à fosfatase ácida (ACP), nossos resultados são diferentes dos relatados por Kummer et al. ${ }^{20}$ (1985), porque estes determinaram-na em placentomas, onde havia maior concentração local da enzima (vacas NRP), observando-se lise fisiológica dos tecidos placentários. Contrariamente, neste trabalho o nível de ACP aumentou nos animais com RP. Os níveis séricos da enzima (Tab. 1) indicam a existência de metabolismo celular do tecido ósseo, lise celular placentária e leucocitária ${ }^{18,29,30,36}$.

Pelos dados obtidos, a atividade da desidrogenase láctica esteve aumentada nos animais RP, concordando com relatos de Dutta; Dugwekar' ( 1982) (Tab. 1). Segundo estes, o aumento das taxas plasmáticas da enzima indicou endometrite e mastite, prioritariamente ao aparecimento dos sinais clínicos.

$A$ relação albumina/globulina $(A / G)$ idealizada pela eletroforese das proteínas plasmáticas no soro indicou queda até 0,3 no grupo de vacas NRP, evidenciando o predomínio das globulinas (Tab. 2). Segundo Bacila' (1980), pastagens excessivamente adubadas elevam a relação $\mathrm{A} / \mathrm{G}$ a 1,3 . Foi relevante o fato de a relação decrescer de 1,3 para 0,3 , revelando aumento produtivo de globulinas e conseqüentemente de anticorpos nos animais NRP. A reação com os animais RP foi inversa. Antes do parto, a relação $\mathrm{A} / \mathrm{G}$ mantinha-se nos padrões fisiológicos (em torno de 0,80 ). Elevou-se para 1,46 no dia do parto, três dias após declinou para I,0 e somente no $5^{\circ}$ dia assemelhou-se à dos animais NRP, reagindo à endometrite e mastite. Pelas evidentes diferenças entre os grupos, a relação $\mathrm{A} / \mathrm{G}$ e as frações de globulina carecem de estudos mais profundos, pois as proteínas monitoram a produção de anticorpos, possibilitando prever o surgimento de RP antes do aparecimento dos sinais clínicos.

Roitt; Brostoff ${ }^{29}(1989)$, Klein $^{18}$ (1990) e Roitt ${ }^{30}$ (1991) ressaltam que as frações alfa, beta e gama das globulinas plasmáticas são importantes para a produção de anticorpos através dos linfócitos $B$, predominantes nos bovinos ${ }^{37}$. Neste experimento, as vacas NRP apresentaram elevadas concentrações de gamaglobulinas, não necessitando das outras frações. Além disso estes animais possuíam 25,0\% a mais de linfócitos que o grupo RP (Fig. 1), o qual utilizouse das frações alfa, beta e gamaglobulina, portando no $5^{\circ}$ dia pós parto somente $70,0 \%$ das globulinas existentes nos animais NRP. Apesar deste fator, os animais com RP apresentaram concentração de $0,7 \mathrm{~g} / \mathrm{dl}$, inferior, por exemplo à fração de gamaglobulina do outro grupo. Esta marcante diferença entre os grupos sugere mais estudos sobre a retenção de placenta e suas complicações, monitoradas pela área imunológica, sinalizando que este quadro indicaria previamente a afecção.

A determinação da IgM no soro sangüíneo revelou concentração fisiológica para ambos os grupos, mas com diferenças significativas entre eles. Segundo Tizard ${ }^{37}$ ( 1987), Roitt; Brostoff ${ }^{29}$ ( 1989), Klein $^{18}$ (1990) e Roitt ${ }^{30}$ (1991), a IgM é a primeira imunoglobulina produzida após ataque ao organismo, e sua determinação no período peripartal é relevante para se conhecer o início da agressão. As vacas RP apresentaram, no dia do parto, somente $60,0 \%$ da concentração encontrada no outro grupo $(221,0$ contra $362,0 \mathrm{mg} / \mathrm{dl}$ respectivamente) (Tab. 2). A diferença pré-partal era de $15,0 \%$, decaindo no dia da parturição, persistindo até o $5^{\circ}$ dia pós parto. Não foi possível concluir se os animais RP produziram menores quantidades da proteína em virtude de endometrite e mastite, ou se a IgM era mais requerida perante outros problemas. Possivelmente as afecções, detectadas pelos sinais clínicos ou por exames laboratoriais após o parto, estariam instalando-se já aos 15 dias antecedentes ao parto. Estes dados sugerem que a taxa de IgM seja determinada no pré-parto, reduzindo assim os índices de endometrite e mastite no puerpério precoce.

Tabela 2

Perfil de imunoglobulinas no soro sanguineo, colostro e leite de vacas holandesas, variedade preta e branca, com e sem retenção de placenta, no $-15^{\circ},-5^{\circ}, 0,+3^{\circ},+5^{\circ}$ dias post partum ( $\left.\mathrm{n}=16\right)$. (Curitiba, PR 1994).

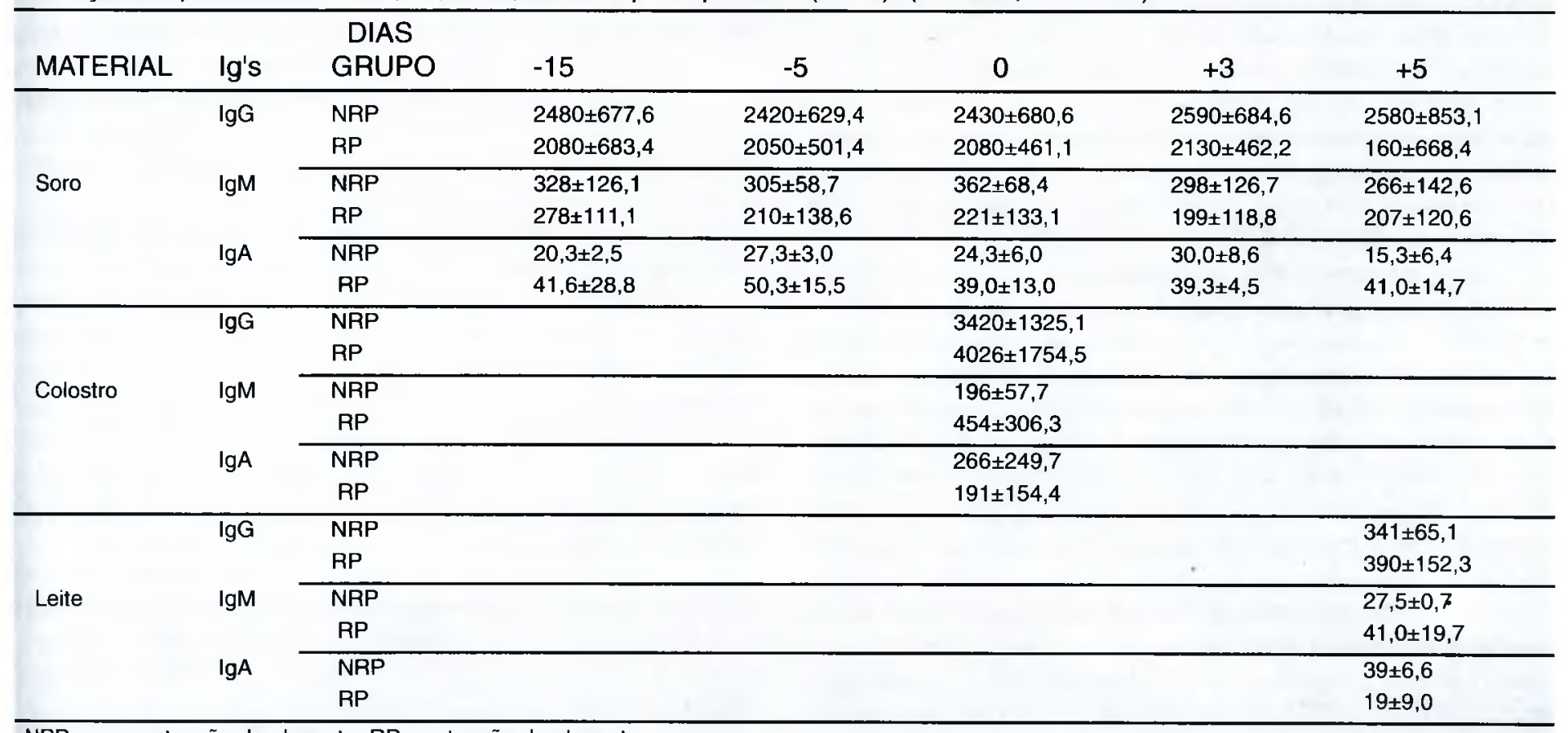

$\mathrm{NRP}=$ sem retenção de placenta; $\mathrm{RP}=$ retenção de placenta 


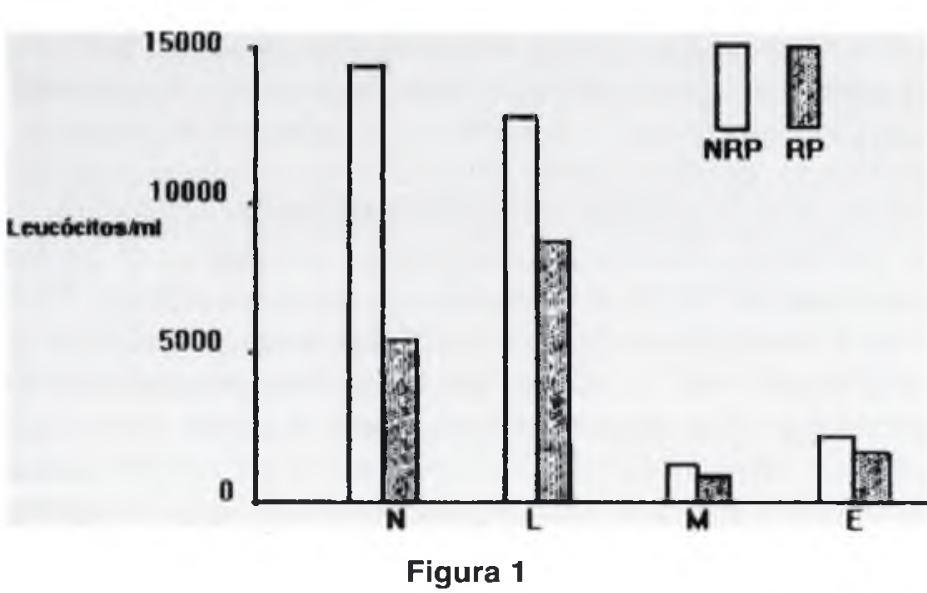

Número de leucócitos circulantes em vacas sem e com retenção de placenta, e a 3 horas após o parto. $[n=39]$. $N=$ neutrófilos; $\mathrm{L}=$ linfócitos; $\mathrm{M}=$ monócitos; $\mathrm{E}=$ eosinófilos; $\mathrm{RP}=$ retenção da placenta; NRP = sem retenção

Com relação à imunoglobulina $\mathrm{G}$ ( $\mathrm{IgG})$, os achados situamse nos limites normais. Ao se compararem as concentrações plasmáticas de IgG entre os grupos, observou-se menor proporção no RP à base de $400 \mathrm{mg} / \mathrm{dl}$ (Tab. 2). A IgG é a segunda imunoglobulina produzida ante as agressões ao organismo segundo Schalm ${ }^{32}$ (1975), Tizard ${ }^{37}$ (1987), Roitt; Brastoff ${ }^{29}$ (1989), Klein ${ }^{18}$ (1990), Roitt" (1991) e Nordhaug et al. ${ }^{26}$ (1994), atingindo níveis elevados quando a IgM diminui suas taxas, sendo possível que algumas das agressões fossem anteriores ao período pesquisado. Os resultados entre os grupos mantiveram-se constantes durante o período pesquisado.

Segundo Roitt; Brastoff ${ }^{29}$ (1989), Klein's (1990), Roitt (1991), a imunoglobulina A (IgA) é secretada ao nível de epitélios e mucosas. Seus níveis plasmáticos são geralmente baixos, quando comparados aos da IgM ou IgG. Os resultados desta pesquisa revelam que as vacas apresentaram concentrações dentro dos limites normais, mas as diferenças percentuais entre os grupos foram maiores que as encontradas para a $\lg$ M ou IgG (Tab. 2). O perfil da IgA no grupo NRP, antes do parto, apresentou apenas $50,0 \%$ da IgA do outro, reduzindo-se para $24,0 \%$ no dia do parto e no $5^{\circ}$ dia elevando-se para aproximadamente $60,0 \%$, indicando segundo Tizard ${ }^{37}$ (1987) agressão a epitélios e mucosas nas vacas problemas. Em razão da importância da IgA nos bovinos, outras pesquisas deverão ser realizadas, podendo-se antever a ocorrência de retenção.

A determinação das imunoglobulinas no colostro revelou situação inversa à do soro, concordando com os dados de Field et al. " (1989). As vacas RP apresentaram concentrações mais elevadas de IgM. IgG e menores de IgA do que as NRP (Tab. 2). O grupo RP apresentou $57,0 \%$ e $15,0 \%$ a mais de IgM e IgG respectivamente do que o outro grupo no dia do parto. Por sua vez, o grupo NRP apresentou $30,0 \%$ a mais de IgA. As amostras de colostro foram colhidas no período intrapartal para mostrar o perfil das três imunoglobulinas e o início da reação imunológica nas vacas $R P$, confirmando a existência de concentrações maiores de IgM e IgG e menores de IgA nestes animais. O quadro evidenciou a presença de mastite aguda, antes do aparecimento de leucócitos, detectados pelo CMT. Pesquisas futuras sobre a IgA devem ser efetuadas para elucidação dos mecanismos que poderiam estar interligados à retenção de placenta seguida de mastite. Segundo Field et al. ${ }^{11}$ (1989), níveis de IgG inferiores a $1500 \mathrm{mg} / \mathrm{dl}$ no colostro representam falência da transferência de imunidade para o bezerro, porque é a imunoglobulina que existe em maior quantidade. Os resultados desta pesquisa sugerem que bezerros de partos com RP, com ou sem endometrite e mastite, recebem menor aporte de IgG do que os de parto NRP. Sugerem-se futuros estudos nesta área.

Determinação de $\lg$, IgG e $\lg$ A no leite pela imunodifusão radial acusou menores concentrações que no colostro (Tab. 2) em ambos os grupos. As diferenças nos teores de IgM entre os grupos apresentaram-se menores nas vacas NRP, demonstrando reação imunológica menos intensa. A IgG permaneceu mais elevada nas vacas RP. Houve $30,0 \%$ a mais de IgA no colostro destes animais, aumentando esta diferença no leite para $50,0 \%$, demonstrando reação imunológica ainda menor, tornando-as mais susceptíveis à mastite (Tab. 2).

Schalm ${ }^{32}$ (1975) estudou as variações dos leucócitos em animais RP e NRP, e Graen ${ }^{13}$ ( 1985 ) relatou quantidades mais elevadas de fagócitos no plasma de vacas NRP, com queda dos teores 24 horas após o parto. Isto foi também observado em vacas com $\mathrm{RP}$, embora possuíssem taxas leucocitárias inferiores às do outro grupo. Nossos resultados concordam com os de Schalm ${ }^{32}$ (1975) e de Graen ${ }^{13}$ ( 1985 ) quanto aos leucócitos circulantes no dia do parto. O leucograma pode indicar a ocorrência de RP antes mesmo do aparecimento dos sinais clínicos. As maiores diferenças no dia da parturição ocorreram entre os polimorfonucleares na proporção de $14500 / \mathrm{ml}$ no grupo NRP contra $5100 / \mathrm{ml}$ no grupo com RP, sinalizando que este possuía somente $35,0 \%$ dos neutrófilos do outro grupo, prejudicando, segundo Schalm ${ }^{32}$ (1975) e Graen'13 (1985), o primeiro ataque aos germes causadores das infecções uterinas agudas. Os eosinófilos estavam elevados em ambos os grupos, mas com diferenças significativas entre eles. Os relatos apresentados por Schalm ${ }^{32}$ (1975) e Graen ${ }^{13}$ (1985) e os nossos resultados permitem concluir que vacas RP deprimem-se nas defesas orgânicas. porque os granulócitos são células fagocíticas muito importantes no útero, placenta e úbere, principalmente no período peripartal. A diferença dos teores de monócitos entre os grupos foi de $25.0 \%$ a mais para o grupo NRP. Considerando-se que os monócitos, ao migrarem da circulação, atuam como poderosos fagócitos, reconhecendo antígenos e participando da comunicação intercelular de defesa do organismo ${ }^{18.28 .30}$, a diferença de $25.0 \%$ entre os grupos significou que 1/4 deles não foi devidamente reconhecido, interferindo nos níveis imunológicos do animal.

Tizard $^{37}$ (1987) relata que os bovinos possuem maior quantidade de linfócitos tipo B e sua linhagem celular secreta imunoglobulinas séricas e teciduais como a $\operatorname{IgM}$, IgG e IgA. $O$ perfil de linfócitos desta pesquisa no dia do parto coincide com os relatos de Schalm ${ }^{32}$ (1975) e de Graen ${ }^{13}$ (1985) ao se verificar, nos animais RP, 31,0\% a menos de células do que no outro grupo $(8650 / \mathrm{ml}$ contra $1250(0 / \mathrm{ml})$. Os linfócitos caíram no pós-parto em ambos os grupos, mas nos animais RP o teor de células somente equiparou-se ao do outro grupo no $5^{\circ}$ dia post partum.

Diversas pesquisas despertaram o interesse dos cientistas pelo fato de a mastite estar associada à retenção de placenta. Heinonen; Heinonen ${ }^{15}$ (1991) verificaram incidência de mastite 3 a 4 vezes maior que o normal em rebanhos leiteiros $(15,0 \%)$, corroborando achados nossos $(62,5 \%)$. Este índice, ao se comparar com as citações de Schukken et al. ${ }^{4}$ (1989), re- 
velou que o surgimento de mastite deu-se em virtude da imunodepressão periférica do animal, associada ao mau manejo e deficiente higiene na ordenha. Destes dados, sugere-se que os animais devam ser submetidos ao CMT regularmente e que as amostras suspeitas sejam encaminhadas ao laboratório para cultura e antibiograma ${ }^{528}$.

\section{CONCLUSÕES}

1) As taxas de colesterol, fósforo inorgânico, fosfatase alcalina e desidrogenase láctica no sangue de vacas NRP foram significativamente menores que as do grupo RP;

2) A relação cálcio/fósforo mostrou-se fisiológica nos animais do grupo NRP e alterada no $\operatorname{RP}(\mathrm{p}<0,01)$ estando a atividade da fosfatase alcalina aumentada em ambos os grupos, porém no grupo RP elevada com significância $(p<0,05)$;

3) Animais RP mobilizaram menor quantidade de Cá ósseo em relação ao outro grupo. Supõe-se que estas vacas estivessem deficientes em receptores do hormônio da paratireóide (PTH) em relação àquelas;

4) A relação albumina/globulina no soro foi significativa- mente maior no grupo $\mathrm{RP}(\mathrm{p}<0,01)$, evidenciando que animais $\mathrm{RP}$ possuem relação maior que 1,0 ;

5) As taxas de alfa, beta e gamaglobulina elevaram-se somente no $3^{\circ}$ e $5^{\circ}$ dias após o parto nas vacas do grupo RP. enquanto nas do NRP foram verificados níveis elevados de gama-globulina no período pré-partal, sugerindo maior capacidade de reação orgânica;

6) Vacas do grupo RP apresentaram significativamente menores concentrações séricas de imunoglobulinas $\mathrm{G}$ e $\mathrm{M}$ e de A nas secreções de colostro e leite $(p<0,01)$, demonstrando baixa capacidade, deste grupo, de gerar anticorpos;

7) Nos animais RP houve decréscimo de $\operatorname{lgG}$ e $\operatorname{lgM}(\mathrm{p}<0,01)$ nas taxas sanguíneas e níveis mais elevados destas imunoglobulinas nas secreções de colostro e leite, evidenciando doenças da glândula mamária;

8) As vacas RP foram mais susceptíveis à mastite $(62,5 \%)$ em consequiência da imunodepressão periférica, associada à resposta imunodeficiente do aparelho mamário;

9) Vacas com RP transferem menor aporte de imunoglobulinas aos bezerros, via colostro e leite, em consequiência das baixas taxas sanguíneas e da mastite.

\section{SUMMARY}

Blood biochemical profiles of 16 Holstein cows with and 23 without placental retention (PR), all on the same diet with $18 \%$ of protein and $70 \%$ of total digestive nutrients (NDT), were compared. Blood samples were taken five times from all animals: on parturiton day (PD) minus 15 days or PD-15; PD-5 days; PD; PD+3 days and PD+5 days. Cows with PR had higher levels of cholesterol ( $p<0.01)$; phosphorus $(P)(p<0.01)$; alkaline phosphatase (ALP) $(p<0.05)$; lactic dehydrogenase (LDH) $(p<0.05)$; aspartateaminotransferase (AST), blood urea nitrogen (BUN) and acid phosphatase (ACP) and lower levels of calcium (Ca). Total protein were normal in both groups but immunoglobulins were lower in cows with $\mathrm{PR}$, probably due to a failure in normal production of $\lg M, \operatorname{lgG}(p<0.01)$ and $\lg A(p<0.01)$ on cholostrum and milk $(p<0.01)$ when compared to those without PR. On calving day, cows with PR had neutrophilia, monocytosis and lymphocytosis; $87.5 \%$ had endometritis and $62.5 \%$ acute mastitis. These data suggest a relationship between immunoglobulin production capacity, circulating white blood cells, uterus and mammary gland inflamation with placental retention, making possible a forecast of fetal annexes retention as far as 15 days before parturition in milking cows.

.UNITERMS: Parturition; Placental retention; Dairy cows; Mastitis.

\section{REFERÊNCIAS BIBLIOGRÁFICAS}

1- BACILA, M. Bioquímica veterinária. São Paulo, Varela, 1980, p.410-23.

2 - CAPAUL, E.G.; I.UCA, L. Placental retention as a metabolic disorder of cows and nutritional way preventing it. Veterinaria Argentina,v. I, p.220-6, 1984.

3 - CHASSAGNE, M; BARNOUIN, J. Circulating PGF2 alfa and nutritional parametrs at parturition in dairy cows with and without retained placenta: relation to prepartum diet. Theriogenology, v.38, n.3, p.407-18, 1992.

4 - CROWLE, A. J. Immunodiffusion. New York, Academic Press, 1961 . p. 10-99.

5-CULLOR, J.S.; TYLER, J W, SMITH, B.P. Distúrbios da glândula mamária. In: SMITH. B.P. Tratado de medicina interna de grandes animais. São Paulo, Manole, 1994. p.1041-60.

6 - DUTTA, J. C; DUGWEKAR,Y.G. Serum alkaline phosphatase and lactic dehydrogenase aclivity in cows with retained fetal membranes. Theriogenology, v. 18, n.4, p.423-9, 1982

7 -EDMONDSON, A.A importância da avaliação corporal no gado leiteiro. Revista Batavo, v.1, p.2-4, 1992

8 -EHLERT, R. Chemolactic activity and leukocyte count in the bovine placentome, with reference to placental detachment. Veterinary Bulletin, v. 55, n. 12, p.992, 7997,1985

9 - FAHEY, J. L.; Mc.KELVEY, E.M. Quantitative determination of serum immunoglobulins in antibody-agarplates. Journal of Immunology, v.94, n. 1, p.84, 1965

10 - FAYEZ, K; GHISHAN, M.D.; PIERCE, E. Placental calcium Iransport: effect of cimetidine. American Journal of Obstetrics and Gynecology, v. 142, p.922-3, 1982.

11 - FIELD, R. W.; BRETZLAFF, K.N.; ELMORE, R.G.; RUPP, G.P. Effect of induction of parturition on immunoglobulin content of colostrum and call serum. Theriogenology, v.32, n.3, p.501-6, 1989.

12 - GONÇALVES, D.; KOZICKI, L.E. Comparação entre taxas de imunoglobulinas "M","G" e "A" no colostro e no leite de vacas com e sem retenção de placenta. In: ENCONTRO PARANAENSE DE MEDICINA VETERINÁRIA, 10. Campo Mourão, 1993. Anais. Campo Mourão, Sociedade Paranaense de Medicina Veterinária, 1993. p. 4.

13 - GRAEN, R. Relationship between the number and activity of leukocytes in the blood of the cows and expulsion of placenta. Hannover, 1985. $253 \mathrm{p}$. Inaugural Dissertation Tierarztliche Hochschule Hannover. 
14 - GUNNINK, J. W. I. Retained placenta leukocytic activity. II. Pre-partum leukocytic activity and retained placenta.III. Post-partum leukocylic activity and relationship to cesarean section and retained placenta.JV. Inlluency of dilution on the chemotactic properties of cotyledon suspensions. Veterinary Quarterly, v.6, p.49-59,1984

15 - HeINONEN, M.: HEINONEN, K. Ritenzione di Placenta nei bovini. Fifetto del Trallamento, o dell non Tratlamento, sulle malattie puerperali e sul consecutivo andamento della fertilitá. Selezione Veterinária, v.22, n.2, p.469-71, 1991

16 - HEUWIESFR, W.; GRUNERT, E. Significance of chemolactic activity for placental expulsion in cattle. Theriogenology, v.27, n.6, p.907-12, 1987.

17 - KAMIYA, S.; DAIGO, M. Prepartum and prolactin-related transeripts distinct from placental lactogen in fetal placenta. Biochemistry, v.28, p. 5161-64, 1988

18 - KI EIN, J. Immunology. Cambridge, Blackwell, 1990. p.31 1-70

19- KOHN. J. Cellulose acetate electrophoresis and immunodiffusion techniques. In: SMITH, I. Chromatographic and electrophorectic techniques, Chicago, v.2. 1976, p.5-134

20 - KUMMER.V.; ZRABY, Z.; CANDERLE, J.; SVECOVA, D. Histological examination of the placentome of cows after induced parturition. Veterinary Medicine, v.32, n.1, p.9-17, 1987

21 - KUMPF, A. Course of puerperal period in cows with placental retencion as indicaled by chemical values in the blood. Veterinary Bulletin. v.55, n. 1 I. p.899, 1985

22 - LESCOURRET, F.; COULON, J.B.; FAYE, B. Predictive model of mastitis ocurence in the dairy cow. Journal of Dairy Science, v.78, n. 10, p. 216777,1995

23 - LOTTHAMMER, L.K. Content of enzymes metabolites, minerals and hormones in the blood of cows before calving, in relation to subsequent placental retention. Tierärztliche Wochenschrift, v.90, p.427-33, 1984

24 - MARTIN. L. R.; WILLIAMS, W.F.; RUSSET, E.; GROSS, T.S. Postpartum uterine motility measurements in dairy cows retained their fetal membranes. Theriogenology, v. 18, p.390-5, 1982.

25 - MYLI.YS, V. Staphylococei in heiler mastitis before and after parturition. Journal of Dairy Research, v. 62, n. 1, p.51-60,1995.

26 - NORIDIIANG. M.L.;NESSE, L.L; NORCROSS, N.L.; GUDDING, R. A field trial with a experimental vaccine against $S$.Aureus mastitis in cattle.2.Antibody responce. Journal of Dairy Science, v. $77, n .1$, p. 1276-84, 1994
27 - OLIVEIRA, A. L.; SOARES, J.B.; (iRLCO, J.B.; GALI7ZI, J.; CANÇAI)O. * J.R. Métodos de laboratório aplicados à clínica: técnica c interpretação.6.ed. Rio de Janeiro, Guanabara Koogan, 1985. p.130-7.

28 - QUINN, P.J.; CARTER. M.E.; MARKEY, B.; CARTER, G.R. Clinical veterinary microbiology, London. Mosby Jaan, 1994. p.330-44.

29 - ROI'T, I.; BROSTOFF, D.M. Imunologia São Paulo, Manole, 1989. p.2.I22.1

30 - ROITT, I. Essential immunology .7ed. Oxford, Blackwell, 1991. p.78-174.

31 - SALA, M.A. Localização ultracstrutural da fosfatase alcalina na placenta normal e a termo. Jornal Brasileiro de (Ginecologia. v.98, p. 185-7, 1988

32 - SCHALM, O. W. Veterinary hematology. $3 \mathrm{ed}$. Philadelphia, Lea \& Febiger. 1975. p.132-6.

33 - SCHUKKEN, Y. E. Retained placenta and mastitis. Cornell Veterinarian, v.79, n.2, p. 129-31, 1989.

34 - SCHUKKEN, Y. E.; ERB, H.N.; SCARLLETT, J.M. A hospital based study of the relationship between retained placenta and mastitis in dairy cows. Cornell Veterinarian, v.79, n.4, p.319-26, 1989

35 - SHALEM, Z. Control of bovine placental progestin synthesis: calcium dependent steroidogenesis is modulated at the site of the cholesterol side chain cleavage enzyme. Journal of Steroid Biochemistry, v.31, p.835-38, 1988.

36 - SILVEIRA, J. M. Patologia clínica veterinária. Interpretação. Rio de Janeiro, Guanabara Koogan, 1988. p.174-87.

37 - TIZARD, I.R. Veterinary immunology 3 ed. Philadelphia, W.B. Saunders, 1987 p. 161-7.

38 - VER, A.; MULLNER ,N.; SZOLLAR, L.; SOMOGYI, J. Oxytocin regulates Ca 2 level in myometrium by influencing phosphoinositide metabolism. Acta Physiologica Academiae Scientiarum Hungaricae, v.74, p. 189-94, 1989.

39 - VUKOVIC, D.; SAMANC, H.; DAMNJANOVIC, Z.; PERKOVIC, S.; IGNJIC, D. Calcium, phosphorus, carotene and vitamin a concentrations in the blood serum of simmental cows with reference to infertility. Veterinarski Glasnik.,v.41, p. 927-30, 1987

40 - WAGNER, W.C. Endocrine physiology of the parturient cows and placental retention. Revista Brasileira de Reprodução Animal, v.2, p.61-7I, 1989

41 - WOICKE, J.; SCHOON, H.-A.; HEUWIESER, W.; SCHULZ, L.-CI.; GRUNERT, E. Morphological and functional aspects of placental maturation mechanisms in the cow. Journal of Veterinary Medicine. Series A. v.33, n.9, p.660-7, 1986. 